CLINICAL STUDY

\title{
A combination of polymorphisms in HSD11B1 associates with in vivo $11 \beta$-HSD 1 activity and metabolic syndrome in women with and without polycystic ovary syndrome
}

\author{
Alessandra Gambineri, Federica Tomassoni, Alessandra Munarini, Roland H Stimson ${ }^{1}$, Roberto Mioni ${ }^{2}$, \\ Uberto Pagotto, Karen E Chapman $^{1}$, Ruth Andrew ${ }^{1}$, Vilma Mantovani, Renato Pasquali and Brian R Walker ${ }^{1}$ \\ Division of Endocrinology, Department of Clinical Medicine, Centre for Applied Biomedical Research (CRBA), S. Orsola-Malpighi Hospital, University of \\ Bologna - Alma Mater Studiorum, Via Massarenti 9, 40138 Bologna, Italy, ${ }^{1}$ Endocrinology Unit, Queen's Medical Research Institute, Centre for \\ Cardiovascular Science, University of Edinburgh, Edinburgh, Scotland, UK and ${ }^{2}$ Division of Internal Medicine, Endocrine-Metabolic Laboratory, University \\ of Padova, Padova, Italy \\ (Correspondence should be addressed to A Gambineri; Email: alessandra.gambineri@aosp.bo.it)
}

\begin{abstract}
Objective: Regeneration of cortisol by $11 \beta$-hydroxysteroid dehydrogenase type 1 (11ß-HSD1) within liver and adipose tissue may be of pathophysiological importance in obesity and the metabolic syndrome. single nucleotide polymorphisms (SNPs) in HSD11B1, the gene encoding 11ß-HSD1, have been associated with type 2 diabetes and hypertension in population-based cohort studies, and with hyperandrogenism in patients with the polycystic ovary syndrome (PCOS). However, the functional consequences of these SNPs for in vivo 11 $\beta$-HSD1 expression and activity are unknown.

Methods: We explored associations of well-characterised hormonal and metabolic phenotypes with two common SNPs (rs846910 and rs12086634) in HSD11B1 in 600 women (300 with PCOS) and investigated 11 $\beta$-HSD1 expression and activity in a nested study of 40 women from this cohort.

Results: HSD11B1 genotypes (as single SNPs and as the combination of the two minor allele SNPs) were not associated with PCOS. Women who were heterozygous for rs846910 A and homozygous for rs12086634 T (GA, TT genotype) had a higher risk of metabolic syndrome, regardless of the diagnosis of PCOS (odds ratio in the whole cohort $=2.77$ (95\% confidence interval $(\mathrm{CI}) 1.16-6.67), P=0.023$ ). In the nested cohort, women with the GA, TT genotype had higher HSD11B1 mRNA levels in adipose tissue, and higher rates of appearance of cortisol and d3-cortisol $(16.1 \pm 0.7 \mathrm{nmol} / \mathrm{min}$ versus $12.1 \pm 1.1, P=0.044)$ during 9,11,12,12-2H4-cortisol (d4-cortisol) steady-state infusion.

Conclusions: We conclude that, in a population of Southern European Caucasian women with and without PCOS, alleles of HSD11B1 containing the two SNPs rs846910 A and rs12086634 T confer increased 11 $\beta$-HSD1 expression and activity, which associates with the metabolic syndrome.
\end{abstract}

European Journal of Endocrinology 165 283-292

\section{Introduction}

HSD11B1(*600713) encodes the enzyme 11 $\beta$-hydroxysteroid dehydrogenase type 1 (11 $\beta$-HSD1), which catalyses regeneration of cortisol from its inactive metabolite cortisone, thereby amplifying glucocorticoid receptor activation, e.g. in liver and adipose tissue (1).

Both increased and decreased 11 $\beta$-HSD1 activity have been implicated in the pathophysiology of common diseases. Glucocorticoid excess, e.g. in Cushing's syndrome, can cause features of the metabolic syndrome, including central obesity, hypertension and glucose intolerance. Transgenic overexpression of 11 $\beta$-HSD1 in liver (2) or adipose tissue (3) in mice increases local glucocorticoid concentrations and recapitulates these features of metabolic syndrome. Conversely, inhibition (4-6) or disruption (7-9) of 11 $\beta$-HSD1 ameliorates features of the metabolic syndrome. In human obesity, 11 $\beta$-HSD1 expression is increased in adipose tissue $(5,10)$ but simultaneously decreased in liver $(10,11)$. Decreased 11 $\beta$-HSD1 expression results in impaired regeneration of cortisol and hence increased metabolic clearance rate for cortisol; the resulting compensatory activation of the hypothalamic-pituitary-adrenal axis may be responsible for adrenal androgen excess in some patients with polycystic ovary syndrome (PCOS) (12-14).

Although a variety of hormonal and nutritional factors regulate $11 \beta$-HSD1 expression $(1,5)$, there is circumstantial evidence that genetic factors contribute to inter-individual variation in cortisol regeneration. Common non-coding single nucleotide polymorphisms (SNPs) in the $5^{\prime}$-flanking region of HSD11B1 (rs846910, G to A) and in an enhancer region in intron 3 (rs12086634, $\mathrm{T}$ to $\mathrm{G}$ ) have been associated 
independently with insulin resistance (15), type 2 diabetes $(15)$ and/or hypertension $(16,17)$ in several studies, although these observations have not been reproduced in all populations (18) and these variants are not associated with obesity. Conversely, the $\mathrm{G}$ allele of rs12086634, which causes lower 11 $\beta$-HSD1 transcriptional activity in vitro (14), is associated with hyperandrogenism among lean women with PCOS (13), although it is not more common among PCOS cases as a whole (19). However, the consequences of these noncoding polymorphisms for $11 \beta$-HSD1 expression and function in vivo have not been determined.

In subcutaneous adipose tissue biopsies, neither rs846910 nor rs12086634 genotype predicted HSD11B1 mRNA in adipocytes in 61 subjects from a native $\mathrm{N}$ American cohort (15). Urinary ratios of cortisol:cortisone metabolites, an indicator of activity of steroid metabolising enzymes including 11 $\beta$-HSD1, are not associated with rs846910 genotype (20, 21).

We performed this study to address the following research questions: i) does the distribution of rs 846910 and rs12086634 gene variants differ between PCOS and controls? ii) are rs846910 A and rs12086634 T genotypes associated with the metabolic syndrome? iii) is this eventual association a characteristic of PCOS or is it present in the whole cohort? iv) do rs846910 and rs12086634 gene variants influence in vivo $11 \beta-H S D 1$ expression and activity?

To answer these questions, we genotyped a cohort of 600 women in whom metabolic and endocrine variables were carefully assessed and half of whom had PCOS, and selected 40 participants with contrasting genotypes for a nested study in which we performed more detailed measurements of $11 \beta$-HSD 1 activity, including stable isotope tracer measurements (22).

\section{Methods}

\section{Participants and protocols for the main cohort}

We investigated 300 unmedicated Caucasian women with PCOS, aged 18-45 years, and 300 Caucasian controls recruited from the general population in Northern Italy, and compared for age and body weight. PCOS women had at least two of the following characteristics: i) chronic oligoanovulation; ii) hirsutism (Ferriman-Gallwey score $\geq 8$ or elevated serum total testosterone levels (23)); iii) polycystic ovarian morphology at ultrasound, according to the Rotterdam consensus conference criteria (24).

Hyperprolactinaemia, Cushing's syndrome, congenital adrenal hyperplasia and androgen-secreting tumors were excluded by laboratory analysis (23). Inclusion criteria for controls were the absence of signs of hyperandrogenism (hirsutism, acne or alopecia) and the presence of regular ovulatory menstrual cycles (progesterone levels $\geq 8 \mathrm{ng} / \mathrm{ml}$ during the luteal phase
(23)). Exclusion criteria for both PCOS and controls were the presence of thyroid dysfunction, cardiovascular, renal or liver diseases screened by clinical examination and routine laboratory findings. Anthropometric data (height, weight, waist and hip circumferences), and systolic and diastolic blood pressure were measured, as described previously (23). All subjects completed a $24 \mathrm{~h}$ urine collection and attended our centre at 0800-0830 h after overnight fast. Basal blood samples for metabolic measurements (glucose, insulin, total cholesterol, HDL-cholesterol and triglycerides) were collected. Samples were immediately chilled on ice and centrifuged, and serum was stored at $-20^{\circ} \mathrm{C}$. Blood samples for DNA extraction were collected in disodium-EDTA and stored at $4{ }^{\circ} \mathrm{C}$. Studies were performed between day 5 and 10 of the menstrual cycle, or during amenorrhoea, after excluding pregnancy by appropriate testing.

The metabolic syndrome was assessed by the National Cholesterol Education Program Expert Panel on Detection, Evaluation and Treatment of High Blood Cholesterol in Adults (NCEP/ATPIII) criteria (25), as we have recently demonstrated the high concordance between the three classifications (NCEP/ATPIII, International Diabetes Federation (IDF) and American Heart Association/National Heart Lung and Blood Institute (AHA/NHLBI)) in diagnosing the metabolic syndrome in PCOS women as well as in controls (26).

NCEP-ATPIII criteria required that an individual meet at least three of the following parameters: i) waist circumference $\geq 88 \mathrm{~cm}$; ii) fasting glucose $\geq 110 \mathrm{mg} / \mathrm{dl}(6.105 \mathrm{mmol} / \mathrm{l})$; iii) triglycerides $\geq 150$ $\mathrm{mg} / \mathrm{dl}$ ( $1.695 \mathrm{mmol} / \mathrm{l})$; iv) HDL-cholesterol $<50 \mathrm{mg} / \mathrm{dl}$ (1.295 $\mathrm{mmol} / \mathrm{l}$ ) and v) blood pressure $\geq 130 / 85 \mathrm{mmHg}$.

\section{Participants and protocols for the nested cohort}

From the main cohort, 40 women were selected to provide approximately balanced groups of subjects with contrasting HSD11B1 genotypes and balanced numbers with or without PCOS within each genotype group. We first randomly selected PCOS subjects from each genotype group and then chose controls matched to each PCOS subject for genotype, age, body weight and waist circumference. These women attended our centre on two further study days. On the first day, they completed a $24 \mathrm{~h}$ urine collection for the measurement of cortisol and its metabolites, and attended after overnight fast. To evaluate adipose 11ß-HSD1 expression and activity, $\sim 300 \mathrm{mg}$ subcutaneous needle aspiration biopsy of subcutaneous adipose tissue from the anterior abdominal wall were obtained and stored at $-80^{\circ} \mathrm{C}$ as described previously (27). After the biopsy procedure, 9,11,12,12-(2H)4-cortisol (d4-cortisol, Cambridge Isotopes, Andover, MA, USA) was infused at 20 molar per cent excess in cortisol (Flebocortid Richer, Sanofi-Aventis S.p.A., Milano, Italy) at 
$1.74 \mathrm{mg} / \mathrm{h}$ after a priming bolus dose of $3.5 \mathrm{mg}$, and blood sampled at intervals for $4 \mathrm{~h}$ (22). d4-Cortisol was administered for estimating whole-body regeneration of cortisol by $11 \beta$-HSD1. The evening prior to the second assessment day, subjects took an oral dose of $1 \mathrm{mg}$ dexamethasone (Decadron, Visufarma S.p.A., Roma, Italy) at $2300 \mathrm{~h}$, for suppressing the endogenous cortisol production, and fasted overnight. At $0800 \mathrm{~h}$, an oral dose of $25 \mathrm{mg}$ cortisone acetate (Cortone Acetato, Giuseppe Rende S.r.L., Roma, Italy) was administered, and blood samples were obtained at intervals for $4 \mathrm{~h}$ to measure plasma cortisol. The conversion of oral cortisone into plasma cortisol allowed us to estimate the activity of $11 \beta$-HSD1 in the liver.

Approval from the ethics committee and informed consent was obtained for all studies, according to the guidelines established by the Institutional Review Board at S. Orsola-Malpighi Hospital and in accordance with the Declaration of Helsinki.

\section{Genotyping}

DNA was extracted using QIAamp DNA Blood Kit (Qiagen, Inc.). Genotyping of rs12086634 and rs846910 was undertaken by single nucleotide primer extension (SNuPE) and denaturing high-performance liquid chromatography (DHPLC), adapted from Hoogendoorn et al. (28). Both HSD11B1 gene fragments were amplified together by PCR for 35 cycles, each consisting of $30 \mathrm{~s}$ at $95^{\circ} \mathrm{C}, 30 \mathrm{~s}$ at $65^{\circ} \mathrm{C}$ and $20 \mathrm{~s}$ at $72{ }^{\circ} \mathrm{C}$. Primers for rs 12086634 were $5^{\prime}$-CTGAGGTTTGCCCAACAAGATTTC-3' (forward) and 5'-CACTGCTGGAGGTGAGTATTAGAG-3' (reverse), and for rs846910, 5'-GCAGCCTCAGCACACTACATTG-3' (forward) and 5'-GTCCCACTTACCAGCCAGAGAG-3' (reverse). Reactions were performed in $10 \mu \mathrm{l}$ final volume using $25 \mathrm{pmol}$ of each primer, $40 \mathrm{ng}$ of genomic DNA, $200 \mu \mathrm{M}$ dNTPs, $2 \mathrm{mM} \mathrm{MgCl} 2$ and 0.08 units of AmpliTaq Gold (Applied Biosystems) in the buffer provided by the manufacturer. PCR products were treated with $2 \mu \mathrm{l}$ Exo-SAP-IT (Amersham Biosciences) to hydrolyse unincorporated nucleotides and degrade primers in excess. Primer extension reactions were carried out in one reaction in $25 \mu$ containing the purified PCR products, $50 \mu \mathrm{M}$ of the appropriate ddNTPs (ddATP, ddGTP and ddCTP), 200 pmol primer and 1.25 units of Thermo Sequenase (Amersham Biosciences) in the buffer provided by the manufacturer. SNuPE reactions were performed in a thermal cycler with 35 cycles each consisting of $30 \mathrm{~s}$ at $94{ }^{\circ} \mathrm{C}, 15 \mathrm{~s}$ at $55^{\circ} \mathrm{C}, 60 \mathrm{~s}$ at $60^{\circ} \mathrm{C}$, followed by $2 \mathrm{~s}$ at $15^{\circ} \mathrm{C}$. Primers were forward $5^{\prime}$-GTTGCTTGTGCTTGATTCCATTTATTCTGGTG-3' for rs12086634 and reverse 5'-GCAAGAGATGGCTATATTAAGAAATC-3' for rs846910. Solution $(10 \mu \mathrm{l})$ containing extended primers was loaded on a SaraSep DNASep column (Transgenomic, San José, CA, USA) at $80^{\circ} \mathrm{C}$ and separated by DHPLC (Wave, Transgenomic) using a linear acetonitrile gradient (over 7 min from 20 to $37 \%$ acetonitrile in 0.1 M triethylamine acetate buffer, $\mathrm{pH} 7$ ) at a constant flow rate of $0.9 \mathrm{ml} / \mathrm{min}$. Data were acquired using a u.v. detector at $260 \mathrm{~nm}$.

To confirm the effectiveness of the method, 100 samples were previously screened by allelic discrimination TaqMan Assay by design (Applied Biosystems) for rs12086634 and by direct sequencing using Big Dye Terminator for rs846910, as described by Nair et al. (15).

\section{Hormone and biochemical assays}

The assays for hormonal and biochemical measurements have been reported elsewhere $(23,29,30)$.

\section{Analyses of d4-cortisol and its metabolites}

Plasma 9,11,12,12-(2H)4-cortisol (d4-cortisol), 9,12,12-(2H)3-cortisone (d3-cortisone) and 9,12,12(2H)3-cortisol (d3-cortisol) were measured by liquid chromatography/tandem mass spectrometry as described previously (31), and tracer kinetics was calculated using the mean of five measurements in steady state between 180 and $240 \mathrm{~min}$ of d4-cortisol infusion. Rate of appearance of $\mathrm{d} 3$-cortisol was calculated as (d4-cortisol infusion rate)/(d4-cortisol:d3-cortisol ratio). Rate of appearance of cortisol was calculated as (d4-cortisol infusion rate)/(d4-cortisol:cortisol ratio) - (cortisol infusion rate).

\section{Analysis of urinary steroids}

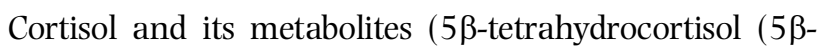
THF), $5 \alpha$-THF, $5 \beta$-tetrahydrocortisone ( $5 \beta$-THE), cortols, cortolones and cortisone) were measured in $24 \mathrm{~h}$ urine by electron impact gas chromatography-mass spectrometry (GC-MS) with minor modifications from a previously described method (32). Briefly, an urine aliquot was equilibrated with internal standards ( $11 \alpha$-epi-THF and $11 \alpha$-hydrocortisone). Steroids were purified by Sep-Pak C18 extraction, and conjugates were hydrolysed with $\beta$-glucuronidase, re-extracted and converted to methoxyamine-trimethylsilylimidazole derivatives, before injection into a GC-MS (Agilent, Santa Clara, CA, USA: GC 6890-MS 5973) in selected ion mode. Cortisol and its metabolites were quantified by the ratio of metabolite:internal standard area against standard curves for each steroid, included in every assay batch. Total cortisol excretion was calculated from the sum of $5 \beta$-THF, $5 \alpha$-THF, $5 \beta$-THE, cortols and cortolones. The balance of $11 \beta$-HSD1 and $11 \beta$-HSD2 activities in all tissues was assessed as the ratio $(5 \alpha-\mathrm{THF}+5 \beta$-THF $) / 5 \beta$-THE, and renal $11 \beta$-HSD 2 activity was assessed as urinary cortisol/cortisone ratio.

\section{Analysis of adipose tissue 11 $\beta$-HSD1 mRNA and protein levels}

Approximately, $500 \mathrm{mg}$ of fat were homogenised in $1 \mathrm{ml}$ TRIzol (Invitrogen), RNA quantified by spectrophotometry, 
and RNA integrity checked by agarose gel electrophoresis. RNA $(1 \mu \mathrm{g})$ was reverse transcribed using the Invitrogen Reverse Transcription System, and transcript levels

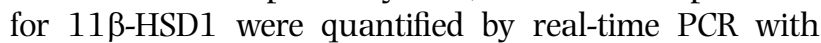
primer-probe sets from PE Applied Biosystems: 5'-GGAATATTCAGTGTCCAGGGTCAA-3' (forward); 5'-TGATCTCCAGGGCACATTCCT-3' (reverse), and 5'-6-FAMCTTGGCCTCATAGACACAGAAACAGCCA-TAMRA-3' (probe). Amplification and detection were performed with the iCycler iQ Real-Time PCR detection system (Bio-Rad Laboratories) with the following profile: 50 cycles consisting of $30 \mathrm{~s}$ at $95^{\circ} \mathrm{C}$ and $60 \mathrm{~s}$ at $60^{\circ} \mathrm{C}$. The real-time PCR amplifications were performed in $25 \mu \mathrm{l}$ reaction volume with $300 \mathrm{mM}$ primers, $300 \mathrm{mM}$ TaqMan probe and $2 \times I Q$ Supermix (Bio-Rad Laboratories). Human cyclophilin A (PE Applied Biosystems) was used to normalise the $11 \beta$-HSD1 transcript levels. A standard curve was generated in triplicate by serial dilution of cDNA pooled from several subjects. Each sample was run in duplicate, and the mean of the duplicates was expressed as a fold difference in RNA level versus an internal control sample. RT negative controls and intron spanning primers were used to control for genomic DNA contamination and prevent its amplification respectively.

To estimate total $11 \beta$-HSD1 protein, activity was measured in the dehydrogenase direction, which is the most stable in vitro, as described previously (10). Briefly, $250 \mathrm{mg}$ tissue were homogenised in KREBS buffer. Total protein $(400 \mu \mathrm{g} / \mathrm{ml})$ was incubated with $2 \mathrm{mM}$ NADP, $0.2 \%$ glucose and $100 \mathrm{nM}$ cortisol (of which $10 \mathrm{nM}$ $1,2,6,7-(3 \mathrm{H}) 4$-cortisol) and incubated at $37^{\circ} \mathrm{C}$ for $30 \mathrm{~h}$. Aliquots were withdrawn at intervals $(6,24$ and $30 \mathrm{~h})$, and conversion to 1,2,6,7-(3H)4-cortisone was measured by HPLC with online scintillation detection.

Results are expressed as picomole of product generated per microgram of homogenised tissue.

\section{Statistical analysis}

The number of cases included in the main cohort was calculated taking into account the previously reported minor allele frequency (MAF; A allele) for SNP rs 846910 of $13 \%$ in PCOS and of $6 \%$ in controls (13); a case-control study of 600 subjects has a power of $80 \%$ to replicate this difference in prevalence at a significance level of $P<0.05$. The number of cases included in the nested cohort was calculated anticipating a difference between genotype groups of at least $20 \%$ in d3-cortisol production and $5 \%$ in $11 \beta-H S D 1$ mRNA level; a case-control study comparing groups of ten subjects has a power of $80 \%$ to detect these differences at a significance level of $P<0.05$.

The distribution of HSD11B1 genotypes (rs846910 and rs12086634) as single SNPs and as the combination of the two SNPs in PCOS cases versus controls was analysed by the $\chi^{2}$ test. It was not possible to classify haplotypes for rs846910 and rs12086634 accurately because of the ambiguity estimated for the haplotypes GT/AG or GG/AT in either PCOS or controls by Arlequin analysis. Whether the distribution of genotypes was consistent with the Hardy-Weinberg equilibrium was examined using the $\chi^{2}$ test, and linkage disequilibrium was measured by Haploview 4.1 Software (http://www.broad.mit.edu/mpg/haploview).

Continuous data were evaluated by one-way or twoway ANOVA, or two-way repeated-measures ANOVA, as appropriate. Bivariate logistic regression was used to estimate the association of the metabolic syndrome or of the individual components of the metabolic syndrome with HSD11B1 genotypes (as a combination of rs846910 and rs12086634) and with PCOS status.

Data are shown as mean \pm s.E.m. and frequencies. Statistical analyses were performed by the SPSS/PC+ version 8 Software package (Chicago, IL, USA). Two-tailed $P$ values $<0.05$ were considered statistically significant.

\section{Results}

\section{Analyses in 600 women with and without PCOS}

The distributions of genotypes for single SNPs and for the combination of the two SNPs in the whole cohort are shown in Table 1. MAF were 0.038 for rs846910 A allele and 0.151 for rs12086634 G allele. No participants were homozygous for rs846910 A allele. The two SNPs did not deviate from the Hardy-Weinberg equilibrium in either group $(P=0.51$ and 0.47$)$ and did not show linkage disequilibrium $\left(D^{\prime}=0.21\right.$ and $\left.r^{2}=0.01\right)$. There were no differences in the prevalence of either SNP or combination of the two SNPs between PCOS cases and controls. Very few participants had

Table 1 Genotype distribution of HSD11B1 single nucleotide polymorphisms (SNPs; rs846910 and rs12086634) shown as single SNP and as the combination of the two SNPs in 300 polycystic ovary syndrome (PCOS) and 300 controls.

\begin{tabular}{lccc}
\hline Genotype & PCOS $n(\%)$ & Controls $n(\%)$ & $\boldsymbol{P}^{*}$ \\
\hline rs846910 & $276(92)$ & $278(93)$ & 0.760 \\
GG & $24(8)$ & $22(7)$ & \\
GA & $0(0)$ & $0(0)$ & \\
AA & & & 0.920 \\
rs12086634 & $216(72)$ & $215(72)$ & \\
TT & $78(26)$ & $79(26)$ & \\
TG & $6(2)$ & $6(2)$ & \\
GG & & & \\
rs846910, rs12086634 & & \\
GG, TT & $199(66.3)$ & $206(68.7)$ & \\
GG, TG & $72(24)$ & $66(22)$ & 610 \\
GG, GG & $5(1.7)$ & $6(2)$ & \\
GA, TT & $17(5.7)$ & $9(3)$ & \\
GA, TG & $6(2)$ & $13(4.3)$ & \\
GA, GG & $1(0.3)$ & $0(0)$ & \\
\hline
\end{tabular}

${ }^{\star} P$ values were calculated by Pearson's $\chi^{2}$.

${ }^{a}$ Genotype is shown as alleles for rs 846910 followed by alleles for rs12086634. 
Table 2 Association between HSD11B1 genotype (as combination of SNPs rs846910 and rs12086634) and the metabolic syndrome by National Cholesterol Education Program Expert Panel on Detection, Evaluation and Treatment of High Blood Cholesterol in Adults criteria in PCOS cases and controls, and in the whole cohort.

\begin{tabular}{|c|c|c|c|c|c|c|c|c|c|}
\hline \multirow[b]{2}{*}{ Genotype $^{a}$} & \multicolumn{3}{|c|}{ PCOS } & \multicolumn{3}{|c|}{ Controls } & \multicolumn{3}{|c|}{ Whole cohort } \\
\hline & $n(\%)$ & OR $(95 \% \mathrm{Cl})$ & $P^{*}$ & $n(\%)$ & OR $(95 \% \mathrm{Cl})$ & $P^{*}$ & $n(\%)$ & OR $(95 \% \mathrm{Cl})$ & $P^{*}$ \\
\hline GG, TT & 45/199 (22.6) & 1.0 (ref) & & $34 / 206(16.5)$ & 1.0 (ref) & & $79 / 405$ (19.5) & 1.0 (ref) & \\
\hline $\begin{array}{l}\text { GG, TG } \\
\text { or GG }\end{array}$ & $12 / 77(15.6)$ & $\begin{array}{l}0.63 \\
\quad(0.32-1.27)\end{array}$ & 0.199 & 4/72 (5.6) & $\begin{array}{l}0.30 \\
(0.10-0.87)\end{array}$ & 0.027 & $16 / 149$ (10.7) & $\begin{array}{l}0.43 \\
\quad(0.23-0.82)\end{array}$ & 0.011 \\
\hline GA, TT & $8 / 17(47.1)$ & $\begin{array}{l}3.04 \\
\quad(1.11-8.34)\end{array}$ & 0.031 & 3/9 (33.3) & $\begin{array}{l}2.53 \\
(0.60-10.61)\end{array}$ & 0.205 & $11 / 26(42.3)$ & $\begin{array}{l}2.77 \\
\quad(1.16-6.67)\end{array}$ & 0.023 \\
\hline $\begin{array}{l}\mathrm{GA}, \mathrm{TG} \\
\quad \text { or } \mathrm{GG}\end{array}$ & $2 / 7(28.6)$ & $\begin{array}{l}1.37 \\
(0.26-7.30)\end{array}$ & 0.713 & $0 / 13(0)$ & $\begin{array}{l}0.001 \\
\quad(0.000-0.026)\end{array}$ & 0.695 & 2/20 (10) & $\begin{array}{l}0.07 \\
\quad(0.00-15.82)\end{array}$ & 0.606 \\
\hline
\end{tabular}

${ }^{*} P$ values were calculated by logistic regression; the interaction between PCOS status and genotype did not enter into the analysis. Metabolic syndrome was associated with PCOS status, regardless of genotype $(\mathrm{PCOS}=67 / 300,22.3 \%$ versus controls $=41 / 300,13.7 \% ; \mathrm{OR}(95 \% \mathrm{CI})=1.82(1.19-2.78) ; P$ value by logistic regression adjusted for genotype $=0.006$.

${ }^{\mathrm{a} G e n o t y p e}$ is shown as alleles for rs 846910 followed by alleles for rs 12086634.

genotypes GA, GG $(n=1)$ or GG, GG $(n=11)$ so they were included in the GA, TG and GG, TG groups, respectively, in further analyses.

There was a significant association between GA, TT genotype and risk of the metabolic syndrome (odds ratio (OR) 2.77, $P=0.023$ ) in the whole cohort, regardless of the diagnosis of PCOS (Table 2). In contrast, the genotype GG, TG or GG, GG was protective against the metabolic syndrome in the whole cohort $(\mathrm{OR}=0.43$, $P=0.011)$. There were no interactions between genotype and PCOS status in predicting the metabolic syndrome (Table 2).

Regarding individual components of the metabolic syndrome, we found that GA, TT genotype was significantly associated with low HDL-cholesterol $(\mathrm{OR}=3.20, \quad P=0.011)$ and with hypertension $(\mathrm{OR}=2.60, P=0.031)$, whereas $\mathrm{GG}$, TG or GG, GG genotype was protective against high waist circumference $(\mathrm{OR}=0.55, P=0.005)$ in the whole cohort, regardless of the diagnosis of PCOS (Table 3). There was no

Table 3 Association between HSD11B1 genotype (as combination of SNPs rs846910 and rs12086634) and individual components of the metabolic syndrome in PCOS cases and controls, and in the whole cohort.

\begin{tabular}{|c|c|c|c|c|c|c|c|c|c|}
\hline \multirow{2}{*}{$\begin{array}{l}\text { Association } \\
\text { of genotype }\end{array}$} & \multicolumn{3}{|c|}{ Pcos } & \multicolumn{3}{|c|}{ Controls } & \multicolumn{3}{|c|}{ Whole cohort } \\
\hline & $n(\%)$ & OR $(95 \% \mathrm{Cl})$ & $P^{*}$ & $n(\%)$ & OR $(95 \% \mathrm{Cl})$ & $P^{*}$ & $n(\%)$ & OR $(95 \% \mathrm{Cl})$ & $P^{*}$ \\
\hline \multicolumn{10}{|l|}{ With high waist } \\
\hline GG, TT & 97/199 (48.7) & 1.0 (ref) & & 77/206 (37.4) & 1.0 (ref) & & $174 / 405$ (43.0) & 1.0 (ref) & \\
\hline GG, TG or GG & $32 / 77(41.6)$ & $0.75(0.44-1.27)$ & 0.284 & $14 / 72(19.4)$ & $0.40(0.21-0.77)$ & 0.006 & $46 / 149(30.9)$ & $0.55(0.37-0.84)$ & 0.005 \\
\hline $\mathrm{GA}, \mathrm{TT}$ & $10 / 17$ (58.8) & $1.50(0.55-4.10)$ & 0.428 & $5 / 9(55.5)$ & $2.09(0.55-8.04)$ & 0.281 & $15 / 26(57.7)$ & $1.77(0.77-4.11)$ & 0.181 \\
\hline $\mathrm{GA}, \mathrm{TG}$ or $\mathrm{GG}$ & $4 / 7(57.1)$ & $1.40(0.31-6.43)$ & 0.664 & $4 / 13(30.8)$ & $0.74(0.22-2.50)$ & 0.633 & $8 / 20(40)$ & $1.02(0.39-2.70)$ & 0.965 \\
\hline GG, TT & $9 / 199(4.5)$ & 1.0 (ref) & & 8/206 (3.9) & 1.0 (ref) & & $17 / 405$ (4.2) & 1.0 (ref) & \\
\hline GG, TG or GG & $3 / 77$ (3.9) & $0.86(0.23-3.25)$ & 0.819 & $3 / 72(4.2)$ & $1.08(0.28-4.17)$ & 0.916 & $6 / 149(4.0)^{\prime}$ & $6(0.37$ & 0.932 \\
\hline GA, TT & $1 / 17(5.9)$ & $16-11.08)$ & 0.799 & $0 / 9(0.0)$ & $-0.05)$ & 0.857 & $1 / 26(3.8)$ & $0-0.08)$ & 0.863 \\
\hline $\mathrm{GA}, \mathrm{TG}$ or $\mathrm{GG}$ & $0 / 7(0.0)$ & $0.01(0.00-0.02)$ & 0.822 & $0 / 13(0.0)$ & $0.00(0.00-0.08)$ & 0.828 & $0 / 20(0.0)$ & $0.00(0.00-0.02)$ & 0.795 \\
\hline \multicolumn{10}{|c|}{ With high triglycerides } \\
\hline GG, TT & $13 / 199(6.5)$ & 1.0 (ref) & & 27/206 (13.1) & 1.0 (ref) & & 40/405 (9.9) & 1.0 (ref) & \\
\hline $\mathrm{GG}, \mathrm{TG}$ or $\mathrm{GG}$ & $7 / 77(9.1)$ & $1.43(0.55-3.73)$ & 0.465 & $5 / 72(6.9)$ & $0.50(0.18-1.34)$ & 0.166 & $12 / 149(8.1)$ & $0.84(0.42-1.68)$ & 0.624 \\
\hline $\mathrm{GA}, \mathrm{TT}$ & 2/17 (11.8) & $1.91(0.39-9.25)$ & 0.423 & $0 / 9(0.0)$ & $0.00(0.00-0.01)$ & 0.826 & $2 / 26(7.7)$ & $0.06(0.00-22.40)$ & 0.779 \\
\hline $\mathrm{GA}, \mathrm{TG}$ or $\mathrm{GG}$ & $1 / 7(14.3)$ & $2.38(0.27-21.31)$ & 0.437 & $0 / 13(0.0)$ & $0.00(0.00-0.02)$ & 0.791 & $1 / 20(5.0)$ & $0.07(0.00-92.90)$ & 0.746 \\
\hline GG, TT & 74/199 (37.2) & 1.0 (ref) & & $34 / 206$ (16.5) & 1.0 (ref) & & $108 / 405(26.7)$ & 1.0 (ref) & \\
\hline GG, TG or GG & $27 / 77(35.1)^{\prime}$ & $0.91(0.53-1.58)$ & 0.743 & $10 / 72(13.9)$ & $0.82(0.38-1.75)$ & 0.601 & $37 / 149(24.8)$ & $0.86(0.54-1.38)$ & 0.538 \\
\hline GA, TT & $12 / 17$ (70.6) & $4.05(1.37-11.96)$ & 0.011 & $3 / 9$ (33.3) & $2.53(0.60-10.61)$ & 0.205 & $15 / 26(57.7)$ & $3.20(1.30-7.86)$ & 0.011 \\
\hline $\mathrm{GA}, \mathrm{TG}$ or $\mathrm{GG}$ & $3 / 7(42.8)$ & $1.27(0.28-5.82)$ & 0.761 & $1 / 13(7.7)$ & $0.42(0.05-3.35)$ & 0.414 & $4 / 20(20.0)$ & $0.73(0.20-2.65)$ & 0.633 \\
\hline \multicolumn{10}{|l|}{ With hypertension } \\
\hline GG, TT & $88 / 199$ (44.2) & 1.0 (ref) & & 61/206 (29.6) & 1.0 (ref) & & $149 / 405(36.8)$ & 1.0 (ref) & \\
\hline $\mathrm{GG}, \mathrm{TG}$ or $\mathrm{GG}$ & $30 / 77(39.0)$ & $0.81(0.47-1.38)$ & 0.429 & $20 / 72(27.8)$ & $0.91(0.50-1$ & 0.769 & $50 / 149(33.6)$ & $0.86(0.57-1.28)$ & 0.454 \\
\hline GA, TT & $9 / 17(52.9)$ & $1.42(0.53-3.83)$ & 0.490 & $6 / 9(66.7)$ & $4.75(1.15-19.63)$ & 0.031 & $15 / 26(57.7)$ & $2.60(1.09-6.17)$ & 0.031 \\
\hline GA, TG or GG & $3 / 7(42.9)$ & $0.95(0.21-4.34)$ & 0.943 & $2 / 13(15.4)$ & $0.43(0.09-2.01)$ & 0.285 & $5 / 20(25)$ & $0.64(0.22-1.89)$ & 0.418 \\
\hline
\end{tabular}

${ }^{*} P$ values were calculated by logistic regression; the interaction between PCOS status and genotype did not enter into the analysis. High waist, low HDLcholesterol and hypertension were associated with PCOS status, regardless of genotype (high waist, PCOS $=143 / 300,47.7 \%$ versus controls $=100 / 300$, $33.3 \%$; OR $(95 \% \mathrm{Cl})=1.82(1.31-2.53) ; P$ value by logistic regression adjusted for genotype $<0.001$; low $\mathrm{HDL}$-cholesterol, $\mathrm{PCOS}=116 / 300,38.7 \%$ versus controls $=48 / 300,16.0 \%$; OR $(95 \% \mathrm{Cl})=3.30(2.25-4.87) ; P$ value by logistic regression adjusted for genotype $<0.001 ;$ hypertension, $\mathrm{PCOS}=130 / 300$, $43.3 \%$ versus controls $=89 / 300,29.7 \%$; OR $(95 \% \mathrm{Cl})=1.81(1.29-2.54) ; P$ value by logistic regression adjusted for genotype $=0.005)$. No significant associations were found between high glucose or high triglycerides and PCOS status.

${ }^{a}$ Genotype is shown as alleles for rs 846910 followed by alleles for rs 12086634 . 
association detected between HSD11B1 genotypes and either high glucose or high triglycerides (Table 3).

Cortisol metabolites were measured in urine to assess relationships between HSD11B1 genotypes and in vivo $11 \beta$-HSD1 activity (Table 4). In accordance with previous reports for individual SNPs $(22,23)$, the combination of rs846910 and rs12086634 SNPs did not predict urinary $(5 \alpha$-THF $+5 \beta$-THF $) / 5 \beta$-THE ratio.

\section{Analyses in 40 women with contrasting HSD11B1 genotypes}

To characterise the effect of HSD11B1 genotypes on in vivo $11 \beta$-HSD1 expression and activity in greater detail, a nested study was conducted in 20 PCOS and 20 control women representing the four most common genotypes (GA, TT, $n=4$ PCOS and $n=4$ controls; GG, TT, $n=6$ PCOS and $n=6$ controls; GA, TG, $n=4$ PCOS and $n=4$ controls; GG, TG, $n=6$ PCOS and $n=6$ controls). The group with the GA, TT genotype had higher whole body rates of appearance of both cortisol (reflecting the combination of adrenal cortisol secretion and net regeneration of cortisol by $11 \beta$-HSD 1 ) and $\mathrm{d} 3$-cortisol (reflecting exclusively the contribution of 11 $\beta$-HSD1 (22)) (Fig. 1A and B). In addition, women with the GA, TT genotype had higher adipose $11 \beta-H S D 1$ mRNA levels (Fig. 1C). The activity of $11 \beta$-HSD1 in the liver (Fig. 2A), measured as appearance of cortisol on first pass conversion after an oral dose of cortisone, and in subcutaneous adipose tissue (Fig. 2B) was not significantly different in women with different genotypes.

\section{Discussion}

In this study, we found that: i) the distribution of rs846910 and rs12086634 gene variants does not differ between PCOS and controls; ii) rs846910 A and rs12086634 T genotype is associated with the metabolic syndrome; iii) this association was evident in the whole cohort; and iv) rs846910 A and rs12086634 T genotype is characterised by increased $11 \beta-H S D 1$ transcript levels in adipose tissue and increased wholebody regeneration of cortisol from cortisone.

Therefore, these results show that Southern European Caucasian women with HSD11B1 alleles containing the two SNPs rs846910 A and rs12086634 $\mathrm{T}$ have increased adipose $11 \beta$-HSD1 expression and increased whole-body 11 $\beta$-HSD1 activity, associated with increased prevalence of the metabolic syndrome. These findings strengthen the evidence that variations in $11 \beta$-HSD1 activity influence the metabolic profile and provide a crucial missing link by demonstrating that HSD11B1 genotypes influence enzyme activity in vivo.

Previous studies of variation in the HSD11B1 gene in native $\mathrm{N}$ American Pima Indians showed that rs846910 and rs12086634 are in complete linkage disequilibrium and independently associate with type 2 diabetes and hypertension $(15,16)$. The discrepancy

Table $424 \mathrm{~h}$ urinary cortisol metabolites in PCOS cases and controls according to HSD11B1 genotypes (as combination of SNPs rs846910 and rs12086634). Data are mean \pm s.E.M. Genotypes are shown as alleles for rs846910 followed by alleles for rs 12086634.

\begin{tabular}{|c|c|c|c|c|c|c|c|}
\hline Variables & $\begin{array}{c}\text { GG, TT } \\
(n=405)\end{array}$ & 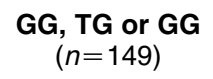 & $\begin{array}{l}\text { GA, TT } \\
(n=26)\end{array}$ & $\begin{array}{c}\text { GA, TG or } \mathbf{~ G G} \\
(n=20)\end{array}$ & $\begin{array}{c}P \text { for } \\
\text { genotypes* }\end{array}$ & $\begin{array}{c}P \text { for } \\
\text { diagnosis }^{*}\end{array}$ & $\begin{array}{c}P \text { for } \\
\text { interaction }\end{array}$ \\
\hline \multicolumn{8}{|c|}{ Cortisol ( $\mu \mathrm{g} /$ days) } \\
\hline PCOS & $101 \pm 4$ & $98 \pm 8$ & $137 \pm 21$ & $140 \pm 23$ & 0.119 & 0.202 & 0.556 \\
\hline Controls & $140 \pm 4$ & $129 \pm 5$ & $90 \pm 4$ & $215 \pm 25$ & & & \\
\hline \multicolumn{8}{|c|}{ Cortisone ( $\mu \mathrm{g} /$ days) } \\
\hline PCOS & $171 \pm 6$ & $170 \pm 10$ & $172 \pm 30$ & $237 \pm 60$ & 0.216 & 0.344 & 0.843 \\
\hline Controls & $224 \pm 8$ & $192 \pm 10$ & $206 \pm 21$ & $308 \pm 68$ & & & \\
\hline \multicolumn{8}{|c|}{ 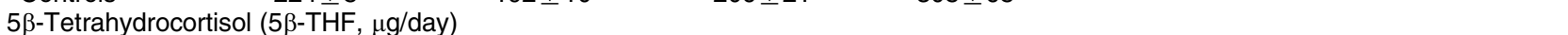 } \\
\hline PCOS & $1681 \pm 65$ & $1711 \pm 123$ & $3266 \pm 620$ & $2042 \pm 449$ & 0.145 & 0.850 & 0.424 \\
\hline \multirow{2}{*}{\multicolumn{8}{|c|}{$5 \alpha-\mathrm{THF}(\mu \mathrm{g} /$ days $)$}} \\
\hline & & & & & & & \\
\hline PCOS & $2404 \pm 117$ & $2110 \pm 238$ & $3900 \pm 740$ & $3539 \pm 984$ & 0.936 & 0.339 & 0.345 \\
\hline Controls & $2579 \pm 122$ & $2526 \pm 237$ & $1613 \pm 165$ & $2238 \pm 106$ & & & \\
\hline \multicolumn{8}{|c|}{$5 \beta$-Tetrahydrocortisone ( $5 \beta-\mathrm{THE}, \mu \mathrm{g} /$ day) } \\
\hline PCOS & $3098 \pm 118$ & $3492 \pm 202$ & $3268 \pm 726$ & $2974 \pm 551$ & 0.986 & 0.785 & 0.605 \\
\hline Controls & $3543 \pm 12$ & $2931 \pm 123$ & $3543 \pm 58$ & $3534 \pm 183$ & & & \\
\hline \multicolumn{8}{|c|}{ Total ( $\mu \mathrm{g} /$ days) } \\
\hline PCOS & $11191 \pm 373$ & $11458 \pm 710$ & $14706 \pm 1966$ & $13722 \pm 2874$ & 0.575 & 0.941 & 0.709 \\
\hline Controls & $12979 \pm 395$ & $10211 \pm 508$ & $12619 \pm 847$ & $12854 \pm 496$ & & & \\
\hline \multicolumn{8}{|c|}{ Cortisol/cortisone } \\
\hline PCOS & $0.639 \pm 0.023$ & $0.593 \pm 0.027$ & $0.843 \pm 0.061$ & $0.671 \pm 0.118$ & 0.865 & 0.660 & 0.734 \\
\hline Controls & $0.716 \pm 0.020$ & $0.732 \pm 0.027$ & $0.471 \pm 0.070$ & $0.874 \pm 0.113$ & & & \\
\hline \multicolumn{8}{|c|}{$(5 \alpha-\mathrm{THF}+5 \beta-\mathrm{THF}) / 5 \beta-\mathrm{THE}$} \\
\hline PCOS & $1.63+0.11$ & $1.08+0.05$ & $3.60+1.15$ & $2.56+1.17$ & 0.523 & 0.195 & 0.510 \\
\hline Controls & $1.65 \pm 0.14$ & $1.34 \pm 0.06$ & $0.98 \pm 0.16$ & $1.27 \pm 0.04$ & & & \\
\hline
\end{tabular}

${ }^{\star} P$ values were calculated by two-way ANOVA; $P$ for genotypes, comparison among the four genotypes; $P$ for diagnosis, comparison between PCOS and controls; $P$ for interaction, evaluation of the interaction between genotypes and diagnosis in the entire population. 

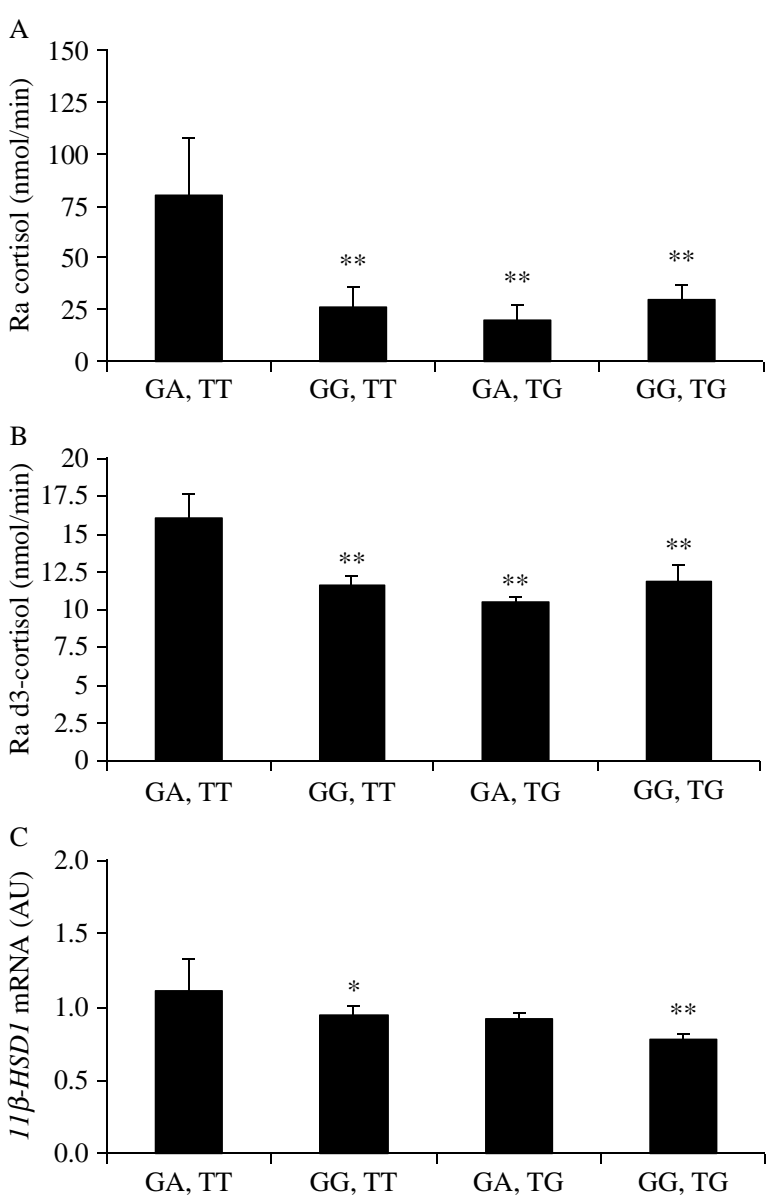

Figure 1 Whole-body $11 \beta$-HSD1 activity, measured by d4-cortisol infusion test, and adipose $11 \beta$-HSD1 expression according to HSD11B1 genotype (as combination of SNPs rs846910 and rs12086634). Data are mean \pm S.E.M. for women with genotypes GA, TT ( $n=4$ PCOS, $n=4$ controls); GG, TT ( $n=6$ PCOS, $n=6$ controls); GA, TG ( $n=4$ PCOS, $n=4$ controls); and GG, TG $(n=6$ PCOS, $n=6$ controls). (A) Rate of appearance of cortisol calculated from dilution of d4-cortisol by unlabelled cortisol during steady-state d4-cortisol infusion. By one-way ANOVA, genotype had an effect $(P=0.040)$. (B) Rate of appearance of d3-cortisol calculated from dilution of d4-cortisol by d3-cortisol during steady-state d4-cortisol infusion. By one-way ANOVA, genotype had an effect $(P=0.044)$. (C) 11 -HSD1 mRNA levels in subcutaneous adipose tissue, expressed as a ratio to cyclophilin internal control. By one-way ANOVA, genotype had an effect $(P=0.041)$. ${ }^{\star} P<0.05$, ${ }^{\star *} P<0.01$ versus GA, TT.

with our results, where we found that the two SNPs do not show linkage disequilibrium, probably depends on the type of population studied. In particular, Pima Indians are genetically homogenous in contrast to Caucasian women, studied by us, who have a great genetic admixture. The allele frequencies in Pima Indians were higher (rs846910 A 13\%; rs12086634 $\mathrm{T} 46 \%$ ), and there was no interaction in that population to suggest that combination of genotypes is important. However, studies in European populations have focused on variants in intron 3 closely linked to rs12086634
(14) and have not found associations with features of metabolic syndrome (18). Our data suggest that, at least in Europeans, alterations associated with the intron 3 enhancer region (14) are insufficient to measurably affect phenotype.

Moreover, a variation in the $5^{\prime}$-flanking region associated with rs846910 is insufficient to alter enzyme activity, consistent with our recent findings that the in vitro $\mathrm{HSD} 11 \mathrm{~B} 1$ promoter activity is the same for both alleles of rs846910, irrespective of the addition of the transcriptional activator, $\mathrm{C} / \mathrm{EBP} \alpha$ (33). However, in this population, the combination of variation in intron 3 and in the $5^{\prime}$-flanking region is sufficient to increase $11 \beta$-HSD1 expression and activity.

This is the first study to undertake comprehensive functional studies of $11 \beta$-HSD1 activity, both whole body and tissue specific, in subjects with contrasting HSD11B1 genotypes. Ratios of cortisol/cortisone metabolites in urine provide an accessible, but imprecise, index of whole-body $11 \beta$-HSD1 activity, because these ratios

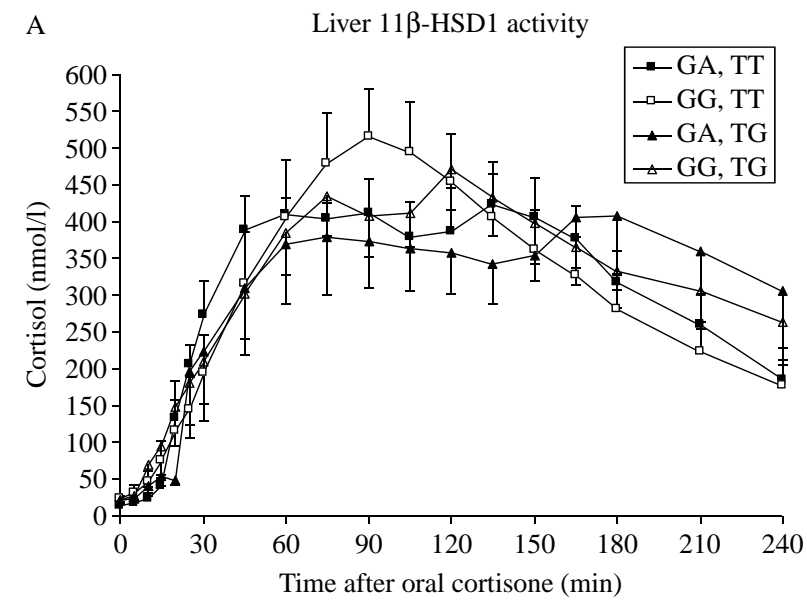

B Subcutaneous adipose tissue 11 $\beta$-HSD1 activity

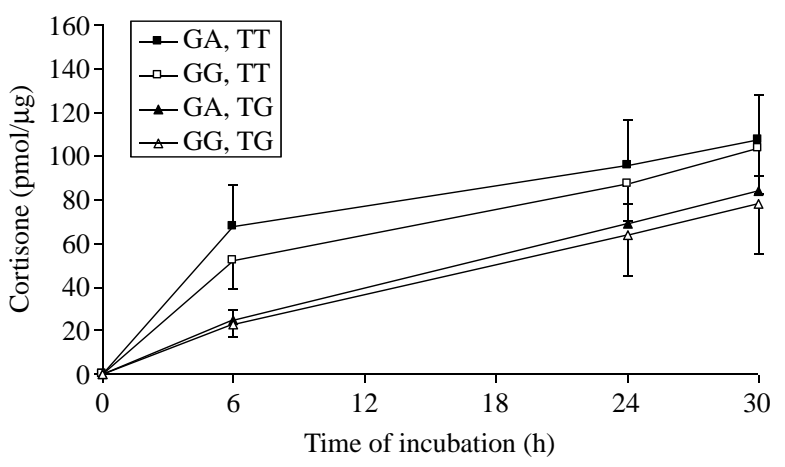

Figure 2 Subcutaneous adipose tissue and liver 11 $\beta$-HSD1 activity according to HSD11B1 genotype (as combination of SNPs rs846910 and rs12086634). Data are mean \pm S.E.M. for women with genotypes GA, TT ( $n=4$ PCOS, $n=4$ controls); GG, TT ( $n=6$ PCOS, $n=6$ controls); GA, TG ( $n=4$ PCOS, $n=4$ controls); and GG, TG ( $n=6$ PCOS, $n=6$ controls). By two-way repeated-measures ANOVA, genotype did not have an effect on activity time course in subcutaneous adipose tissue $(P=0.553)$ or liver $(P=0.998)$. 
are influenced by the activity of other enzymes, such as $11 \beta$-HSD2 and reductases. Similar to other reports $(20,21)$, we did not find any relationship between HSD11B1 genotypes and urinary cortisol/cortisone metabolite ratios (Table 4 ). Whole-body regeneration of cortisol by $11 \beta$-HSD1 can be measured specifically using the d4-cortisol stable isotope tracer $(22,34,35)$. The rate of appearance of $\mathrm{d} 3$-cortisol was strikingly higher in women with the GA, TT HSD11B1 genotype. The major source of extra-adrenal cortisol regeneration is the liver $(34,35)$, but recent data confirm that there is a contribution from adipose tissue (31).

Liver $11 \beta$-HSD1 can be measured without hepatic vein cannulation by administering oral cortisone and measuring the initial rate of appearance of cortisol in peripheral plasma after first pass hepatic metabolism (35). Using this tool, we did not find an association between HSD11B1 genotype and liver 11 $\beta$-HSD1 activity. However, in subcutaneous adipose tissue, women with the GA, TT genotype had higher $11 \beta$ HSD1 transcript levels. Tissue-specific dysregulation of $11 \beta$-HSD1 is well established in obesity in rodents and humans $(1,10)$, and may relate in part to tissue-specific use of promoters (36) and/or to differential effects of $\mathrm{C} / \mathrm{EBP}$ transcription factors in liver and adipose (37); the promoter activity may be influenced by genetic variation.

There is good evidence that genetic variation in the gene encoding hexose-6-phosphate dehydrogenase (H6PDH) influences 11 $\beta$-HSD1 activity by controlling availability of cofactor NADPH within the endoplasmic reticulum $(14,38,39)$. Profound deficiency in $11 \beta$-HSD1 activity appears to result from mutations in H6PDH rather than HSD11B1 (14). However, we did not investigate the role of $\mathrm{H6PDH}$ in this study, because mutations in $H 6 P D H$ are too rare to obtain adequate statistical power in this cohort.

Genetic association studies must be interpreted cautiously in view of the risk of false positives. However, several observations suggest that the associations of HSD11B1 genotype with metabolic syndrome observed in this study are not spurious. Variants in HSD11B1 have been associated with the metabolic syndrome in other cohorts (15-17) but are not included in the chips that have been used commonly in genome-wide association studies to date. We have shown that HSD11B1 genotype predicts variation in enzyme function, and we know from numerous studies in animal models and in humans that variations in $11 \beta$-HSD1 activity influence metabolic syndrome variables (1). The association of HSD11B1 genotypes with the metabolic syndrome was driven primarily by links with low HDL-cholesterol and high blood pressure; HSD11B1 genotype was not closely linked with glucose homeostasis or hypertriglyceridaemia. In mice, increased $11 \beta$-HSD1 activity selectively in liver (2) or adipose tissue (3) is sufficient to induce hypertension and hyperinsulinaemia, while cross-sectional studies in humans describe associations of adipose 11 $\beta$-HSD1 expression with insulin sensitivity and blood pressure (40). Although the relative youth of this cohort of women may mitigate against detecting effects on glucose, this observation may be important in highlighting different consequences of variations in $11 \beta$-HSD1 in mice and humans.

Our results confirm previous reports that variants in HSD11B1 are not associated with the prevalence of PCOS $(19,20)$ and extend these findings to include rs846910 and its combination with rs12086634.

In conclusion, complex variations in the HSD11B1 gene have functional consequences for enzyme activity in vivo, particularly in adipose tissue, which influence fat distribution and its metabolic consequences. These findings reinforce the importance of $11 \beta$-HSD1 as a pathophysiological mediator and therapeutic target in the metabolic syndrome.

\section{Declaration of interest}

The authors declare that there is no conflict of interest that could be perceived as prejudicing the impartiality of the research reported.

\section{Funding}

This research did not receive any specific grant from any funding agency in the public, commercial or not-for-profit sector.

\section{Acknowledgements}

We thank Vincenzo Cerreta, Jill Harrison and Alison Rutter for their assistance and technical advice, and the staff of the Wellcome Trust Clinical Research Facility Mass Spectrometry Core Laboratory for their technical support. We also thank Fondazione Cassa di Risparmio in Bologna for supporting the Centre for Applied Biomedical Research.

\section{References}

1 Seckl JR \& Walker BR. 11ß-Hydroxysteroid dehydrogenase type 1 - a tissue-specific amplifier of glucocorticoid action. Endocrinology 2001142 1371-1376. (doi:10.1210/en.142.4.1371)

2 Paterson JM, Morton NM, Fievet C, Kenyon CJ, Holmes MC, Staels B, Seckl JR \& Mullins JJ. Metabolic syndrome without obesity: hepatic overexpression of $11 \beta$-hydroxysteroid dehydrogenase type 1 in transgenic mice. PNAS 2004101 7088-7093. (doi:10.1073/pnas.0305524101)

3 Masuzaki H, Paterson J, Shinyama H, Morton NM, Mullins JJ, Seckl JR \& Flier JS. A transgenic model of visceral obesity and the metabolic syndrome. Science 2001294 2166-2170. (doi:10. $1126 /$ science.1066285)

4 Walker BR, Connacher AA, Lindsay RM, Webb DJ \& Edwards CRW. Carbenoxolone increases hepatic insulin sensitivity in man: a novel role for 11-oxosteroid reductase in enhancing glucocorticoid receptor activation. Journal of Clinical Endocrinology and Metabolism 199580 3155-3159. (doi:10.1210/jc.80.11.3155)

5 Hughes KA, Webster SP \& Walker BR. 11-Beta-hydroxysteroid dehydrogenase type 1 (11beta-HSD1) inhibitors in type 2 diabetes mellitus and obesity. Expert Opinion on Investigational Drugs 2008 17 481-496. (doi:10.1517/13543784.17.4.481)

6 Alberts P, Engblom L, Edling N, Forsgren M, Klingstrom G, Larsson C, Ronquist-Nii Y, Ohman B \& Abrahmsen L. Selective inhibition 
of 11beta-hydroxysteroid dehydrogenase type 1 decreases blood glucose concentrations in hyperglycaemic mice. Diabetologia 2002 45 1528-1532. (doi:10.1007/s00125-002-0959-6)

7 Kotelevtsev YV, Holmes MC, Burchell A, Houston PM, Scholl D, Jamieson PM, Best R, Brown RW, Edwards CRW, Seckl JR \& Mullins JJ. 11ß-Hydroxysteroid dehydrogenase type 1 knockout mice show attenuated glucocorticoid inducible responses and resist hyperglycaemia on obesity and stress. PNAS $1997 \mathbf{9 4}$ 14924-14929. (doi:10.1073/pnas.94.26.14924)

8 Morton NM, Holmes MC, Fievet C, Staels B, Tailleux A, Mullins JJ \& Seckl JR. Improved lipid and lipoprotein profile, hepatic insulin sensitivity, and glucose tolerance in $11 \beta$-hydroxysteroid dehydrogenase type 1 null mice. Journal of Biological Chemistry 2001276 41293-41300. (doi:10.1074/jbc.M103676200)

9 Morton NM, Paterson JM, Masuzaki H, Holmes MC, Staels B, Fievet C, Walker BR, Flier JS, Mullins JJ \& Seckl JR. Novel adipose tissue-mediated resistance to diet-induced visceral obesity in $11 \beta$ hydroxysteroid dehydrogenase type 1 deficient mice. Diabetes 2004 3 931-938. (doi:10.2337/diabetes.53.4.931)

10 Rask E, Olsson T, Soderberg S, Andrew R, Livingstone DEW Johnson $\mathrm{O} \&$ Walker BR. Tissue-specific dysregulation of cortisol metabolism in human obesity. Journal of Clinical Endocrinology and Metabolism 200186 1418-1421. (doi:10.1210/jc.86.3.1418)

11 Stewart PM, Boulton A, Kumar S, Clark PMS \& Shackleton CHL. Cortisol metabolism in human obesity: impaired cortisone-cortisol conversion in subjects with central adiposity. Journal of Clinical Endocrinology and Metabolism 199984 1022-1027. (doi:10.1210/ jc.84.3.1022)

12 Rodin A, Thakkar H, Taylor N \& Clayton R. Hyperandrogenism in polycystic ovary syndrome: evidence of dysregulation of 11 betahydroxysteroid dehydrogenase. New England Journal of Medicine 1994330 460-465. (doi:10.1056/NEJM199402173300703)

13 Gambineri A, Vicennati V, Tomassoni F, Pagotto U, Pasquali R \& Walker BR. Genetic variation in 11ß-hydroxysteroid dehydrogenase type 1 predicts hyperandrogenism amongst lean women with polycystic ovary syndrome. Journal of Clinical Endocrinology and Metabolism 200691 2295-2302. (doi:10.1210/jc.2005-2222)

14 Draper N, Walker EA, Bujalska IJ, Tomlinson JW, Chalder SM, Arlt W, Lavery G, Bedendo O, Ray DW, Laing I, Malunowicz E, White PC, Hewison M, Mason PJ, Connell JM, Shackleton CHL \& Stewart PM. Mutations in the genes encoding 11 $\beta$-hydroxysteroid dehydrogenase type 1 and hexose-6-phosphate dehydrogenase interact to cause cortisone reductase deficiency. Nature Genetics 200334 434-439. (doi:10.1038/ng1214)

15 Nair S, Lee YH, Lindsay RS, Walker BR, Tataranni PA, Bogardus C, Baier LJ \& Permana PA. 11Beta-hydroxysteroid dehydrogenase type 1: genetic polymorphisms are associated with type 2 diabetes in Pima Indians independently of obesity and expression in adipocyte and muscle. Diabetologia 200447 1088-1095. (doi:10. 1007/s00125-004-1407-6)

16 Franks PW, Knowler WC, Nair S, Koska J, Lee Y-H, Lindsay RS, Walker BR, Looker HC, Permana PA, Tataranni PA \& Hanson RL. Interaction between an 11beta HSD1 gene variant and birth era modifies the risk of hypertension in Pima Indians. Hypertension 2004 44 681-688. (doi:10.1161/01.HYP.0000144294.28985.d5)

17 Morales MA, Carvajal CA, Ortiz E, Mosso LM, Artigas RA, Owen GI \& Fardella CE. Possible pathogenetic role of 11 beta-hydroxysteroid dehydrogenase type 1 (11beta HSD1) gene polymorphisms in arterial hypertension. Revista Médica de Chile 2008136 701-710. (doi:10.4067/S0034-98872008000600003)

18 Smit P, Dekker MJ, de Jong FJ, Van Den Beld AW, Koper JW, Pols HA, Brinkmann AO, de Jong FH, Breteler MM \& Lamberts SW. Lack of association of the 11beta-hydroxysteroid dehydrogenase type 1 gene 83,557ins A and hexose-6-phosphate dehydrogenase gene $\mathrm{R} 453 \mathrm{Q}$ polymorphisms with body composition, adrenal androgen production, blood pressure, glucose metabolism, and dementia. Journal of Clinical Endocrinology and Metabolism 200792 359-362. (doi:10.1210/jc.2006-1349)

19 Draper N, Powell BL, Franks S, Conway GS, Stewart PM \& McCarthy MI. Variants implicated in cortisone reductase deficiency do not contribute to susceptibility to common forms of polycystic ovary syndrome. Clinical Endocrinology $2006 \mathbf{6 5} 64$ 70. (doi:10.1111/j.1365-2265.2006.02547.x)

20 Millan JL, Botella-Carratero JI, Alvarez-Blasco F, LuqueRamirez M, Sancho J, Moghetti P \& Escobar-Morreal HF. A study of the hexose-6-phosphate dehydrogenase gene R453Q and 11 beta-hydroxysteroid dehydrogenase type 1 gene 83557 insA polymorphisms in the polycystic ovary syndrome. Journal of Clinical Endocrinology and Metabolism 200590 4157-4162. (doi:10.1210/jc.2004-1523)

21 White PC. Genotypes at 11beta-hydroxysteroid dehydrogenase type 11B1 and hexose-6-phosphate dehydrogenase loci are not risk factors for apparent cortisone reductase deficiency in a large population-based sample. Journal of Clinical Endocrinology and Metabolism 200590 5880-5883. (doi:10.1210/jc.2005-0942)

22 Andrew R, Smith K, Jones GC \& Walker BR. Distinguishing the activities of 11ß-hydroxysteroid dehydrogenases in vivo using isotopically labelled cortisol. Journal of Clinical Endocrinology and Metabolism 200287 277-285. (doi:10.1210/jc.87.1.277)

23 Gambineri A, Pelusi C, Genghini S, Morselli-Labate AM, Cacciari M, Pagotto U \& Pasquali R. Effect of flutamide and metformin administered alone or in combination in dieting obese women with polycystic ovary syndrome. Clinical Endocrinology 200460 241-249. (doi:10.1111/j.1365-2265.2004.01973.x)

24 The Rotterdam ESHRE/ASMR-sponsored PCOS consensus workshop group. Revised 2003 consensus on diagnostic criteria and long-term health risks related to polycystic ovary syndrome Human Reproduction 2004 19 41-47. (doi:10.1093/humrep/deh098)

25 Expert Panel on Detection, Evaluation, and Treatment of High Blood Cholesterol in Adults. Executive summary of the Third Report of the National Cholesterol Education Program (NCEP) Expert Panel on Detection, Evaluation, and Treatment of High Blood Cholesterol in Adults (Adult Treatment Panel III). Journal of the American Medical Association 2001285 2486-2497. (doi:10.1001/jama.285.19.2486)

26 Gambineri A, Repaci A, Patton L, Grassi I, Pocognoli P, Cognigni GE, Pasqui F, Pagotto U \& Pasquali R. Prominent role of low HDL-cholesterol in explaining the high prevalence of the metabolic syndrome in polycystic ovary syndrome. Nutrition, Metabolism, and Cardiovascular Diseases 200919 797-804. (doi:10.1016/j.numecd.2009.01.007)

27 Stimson RH, Johnstone AM, Homer NZ, Wake DJ, Morton NM, Andrew R, Lobley GE \& Walker BR. Dietary macronutrient content alters cortisol metabolism independently of body weight changes in obese men. Journal of Clinical Endocrinology and Metabolism 2007 92 4480-4484. (doi:10.1210/jc.2007-0692)

28 Hoogendoorn B, Owen MJ, Oefner PJ, Williams N, Austin J \& O'Donovan MC. Genotyping single nucleotide polymorphisms by primer extension and high performance liquid chromatography. Human Genetics $1999 \mathbf{1 0 4}$ 89-93. (doi:10.1007/ s004390050915)

29 Vicennati V \& Pasquali R. Abnormalities of the hypothalamicpituitary-adrenal axis in nondepressed women with abdominal obesity and relations with insulin resistance: evidence for a central and a peripheral alteration. Journal of Clinical Endocrinology and Metabolism 2000 85 4093-4098. (doi:10.1210/jc.85.11.4093)

30 Pasquali R, Gambineri A, Anconetani B, Vicennati V, Colitta D, Caramelli E, Casimirri F \& Morselli-Labate AM. The natural history of the metabolic syndrome in young women with the polycystic ovary syndrome and the effect of long-term oestrogenprogestagen treatment. Clinical Endocrinology 199950 517-527. (doi:10.1046/j.1365-2265.1999.00701.x)

31 Stimson RH, Andersson J, Andrew R, Redhead DN, Karpe F, Hayes PC, Olsson T \& Walker BR. Cortisol release from adipose tissue by 11 beta-hydroxysteroid dehydrogenase type 1 in humans. Diabetes 200958 46-53. (doi:10.2337/db08-0969)

32 Best R \& Walker BR. Additional value of measurement of urinary cortisone and unconjugated cortisol metabolites in assessing the activity of $11 \beta$-hydroxysteroid dehydrogenase in vivo. Clinical Endocrinology 1997 47 231-236. (doi:10.1046/j.1365-2265.1997.2471061.x)

33 Malavasi EL, Kelly V, Nath N, Gambineri A, Dakin RS, Pagotto U, Pasquali R, Walker BR \& Chapman KE. Functional effects of 
polymorphisms in the human gene encoding 11beta hydroxysteroid dehydrogenase type 1 (11 beta-HSD1): a sequence variant at the translation start of 11 beta-HSD1 alters enzyme levels. Endocrinology 2010151 195-202. (doi:10.1210/en.2009-0663)

34 Basu R, Singh RJ, Basu A, Chittilapilly EG, Johnson CM, Toffolo G, Cobelli C \& Rizza RA. Splanchnic cortisol production occurs in humans - evidence for conversion of cortisone to cortisol via the 11- $\beta$ hydroxysteroid dehydrogenase type 1 pathway. Diabetes 200453 2051-2059. (doi:10.2337/diabetes.53.8.2051)

35 Andrew R, Westerbacka J, Wahren J, Yki-Jarvinen H \& Walker BR. The contribution of visceral adipose tissue to splanchnic cortisol production in healthy humans. Diabetes 200554 1364-1370. (doi:10.2337/diabetes.54.5.1364)

36 Bruley C, Lyons V, Worsley AG, Wilde MD, Darlington GD, Morton NM, Seckl JR \& Chapman KE. A novel promoter for the 11beta-hydroxysteroid dehydrogenase type 1 gene is active in lung and is C/EBPalpha independent. Endocrinology $2006 \mathbf{1 4 7}$ 2879-2885. (doi:10.1210/en.2005-1621)

37 Sai S, Esteves CL, Kelly V, Michailidou Z, Anderson K, Coll AP, Nakagawa Y, Ohzeki T, Seckl JR \& Chapman KE. Glucocorticoid regulation of the promoter of 11beta-hydroxysteroid dehydrogenase type 1 is indirect and requires CCAAT/enhancer-binding protein-beta. Molecular Endocrinology 200822 2049-2060. (doi:10.1210/me.2007-0489)
38 Lavery G, Walker EA, Draper N, Jeyasuria P, Marcos J, Shackleton CHL, Parker KL, White PC \& Stewart PM. Hexose-6-phosphate dehydrogenase knock-out mice lack $11 \beta$ hydroxysteroid dehydrogenase type 1-mediated glucocorticoid regeneration. Journal of Biological Chemistry $2006 \mathbf{2 8 1}$ 6546-6551. (doi:10.1074/jbc.M512635200)

39 Lavery GG, Walker EA, Tiganescu A, Ride JP, Shackleton CH, Tomlinson JW, Connell JM, Ray DW, Biason-Lauber A, Malunowicz EM, Arlt W \& Stewart PM. Steroid biomarkers and genetic studies reveal inactivating mutations in hexose-6phosphate dehydrogenase in patients with cortisone reductase deficiency. Journal of Clinical Endocrinology and Metabolism 2008 93 3827-3832. (doi:10.1210/jc.2008-0743)

40 Wake DJ, Rask E, Livingstone DEW, Soderberg S, Olsson T \& Walker BR. Local and systemic impact of transcriptional

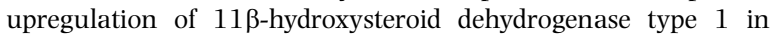
adipose tissue in human obesity. Journal of Clinical Endocrinology and Metabolism 200388 2983-2988. (doi:10.1210/jc.2003030286)

Received 27 April 2011

Accepted 27 May 2011 